\title{
Controlled Trafficking of Multiple and Diverse Cations Prompts
}

\section{Nucleic Acid Hydrolysis}

\author{
Jacopo Manigrasso, ${ }^{1,2}$ Marco De Vivo ${ }^{1, *}$ and Giulia Palermo ${ }^{2,3, *}$
}

1. Laboratory of Molecular Modelling \& Drug Discovery, Istituto Italiano di Tecnologia, Via Morego 30, 16163, Genoa, Italy

2. Department of Bioengineering and 3. Department of Chemistry, University of California Riverside, 900 University Avenue, Riverside, CA 52512, United States

Corresponding author:

Dr. Giulia Palermo (giulia.palermo@ucr.edu)

Dr. Marco De Vivo (marco.devivo@,iit.it)

Table of contents

1. Supplementary Figures 


\section{SUPPLEMENTARY FIGURES}

A

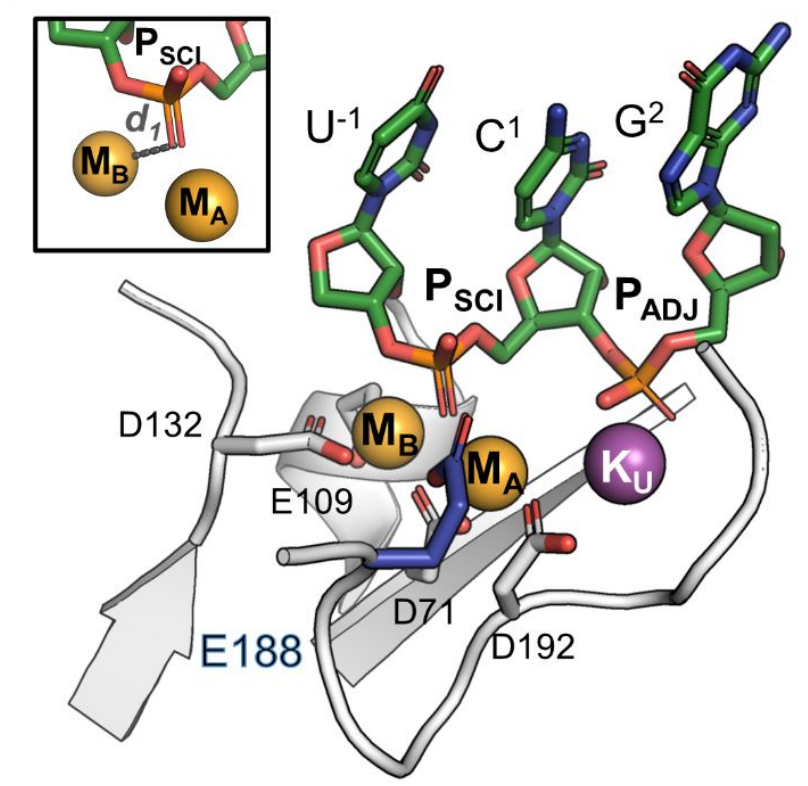

\section{B}

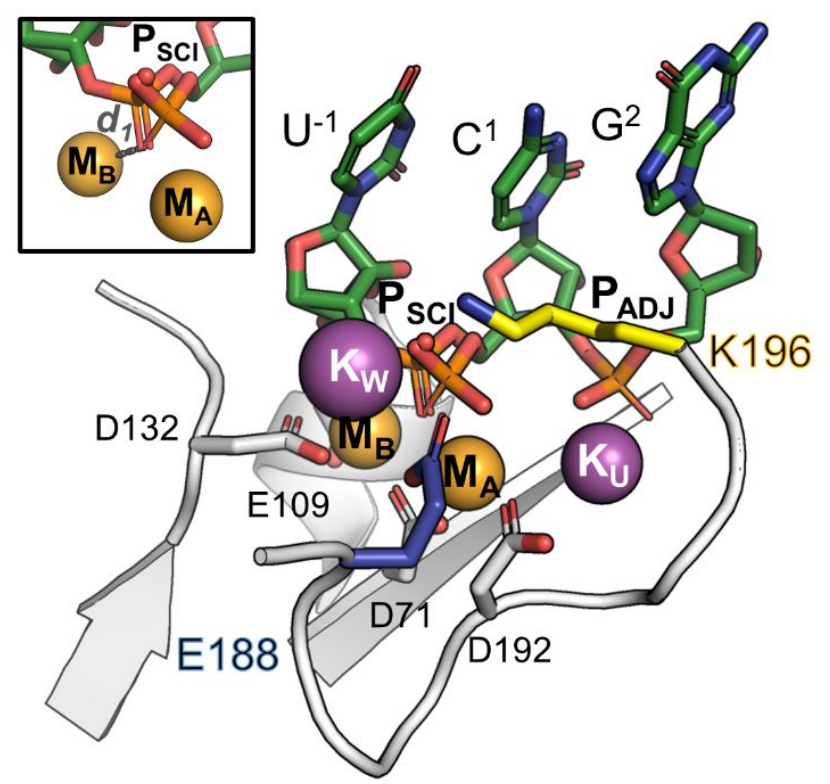

Figure S1. Reaction intermediates of wild type RNase H1 as captured by X-ray crystallography.

(A) The reactant state of RNase H1 as obtained after 40s from the incubation (PDBid: 6DMV). The catalytic residues forming the DEDD motif (viz. D71, E109, D132, and D192; white) and the residue E188 (blue) are represented as sticks. The RNA nucleotides (green) including the scissile phosphate $\left(\mathrm{P}_{\mathrm{SCI}}\right)$ and its adjacent phosphate $\left(\mathrm{P}_{\mathrm{ADJ}}\right)$ are also shown as sticks. The two catalytic magnesium ions $\mathrm{M}_{\mathrm{A}^{-}}$ $\mathrm{M}_{\mathrm{B}}$ (orange) and the ion $\mathrm{K}_{\mathrm{U}}$ (purple) are shown as spheres. Notably, at this stage, $\mathrm{K}_{\mathrm{W}}$ is not found at the active site, the $\mathrm{P}_{\mathrm{SCI}}$ is not properly aligned onto the catalytic $\mathrm{M}_{\mathrm{A}}-\mathrm{M}_{\mathrm{B}}$ (i.e., $\mathrm{d} 1=2.6 \AA$, left corner), and the products are not formed. (B) The reactant state of RNase $\mathrm{H} 1$ as obtained after 120s from the incubation (PDBid: 6DO9). Here, K196 (yellow) is represented as sticks, while the additional $\mathrm{K}_{\mathrm{W}}$ (purple) is shown as a sphere. Importantly, at this stage, the Michaelis-Menten complex is properly formed (i.e., $\mathrm{d} 1=2.2 \AA$, left corner), and the formation of the products is observed. 

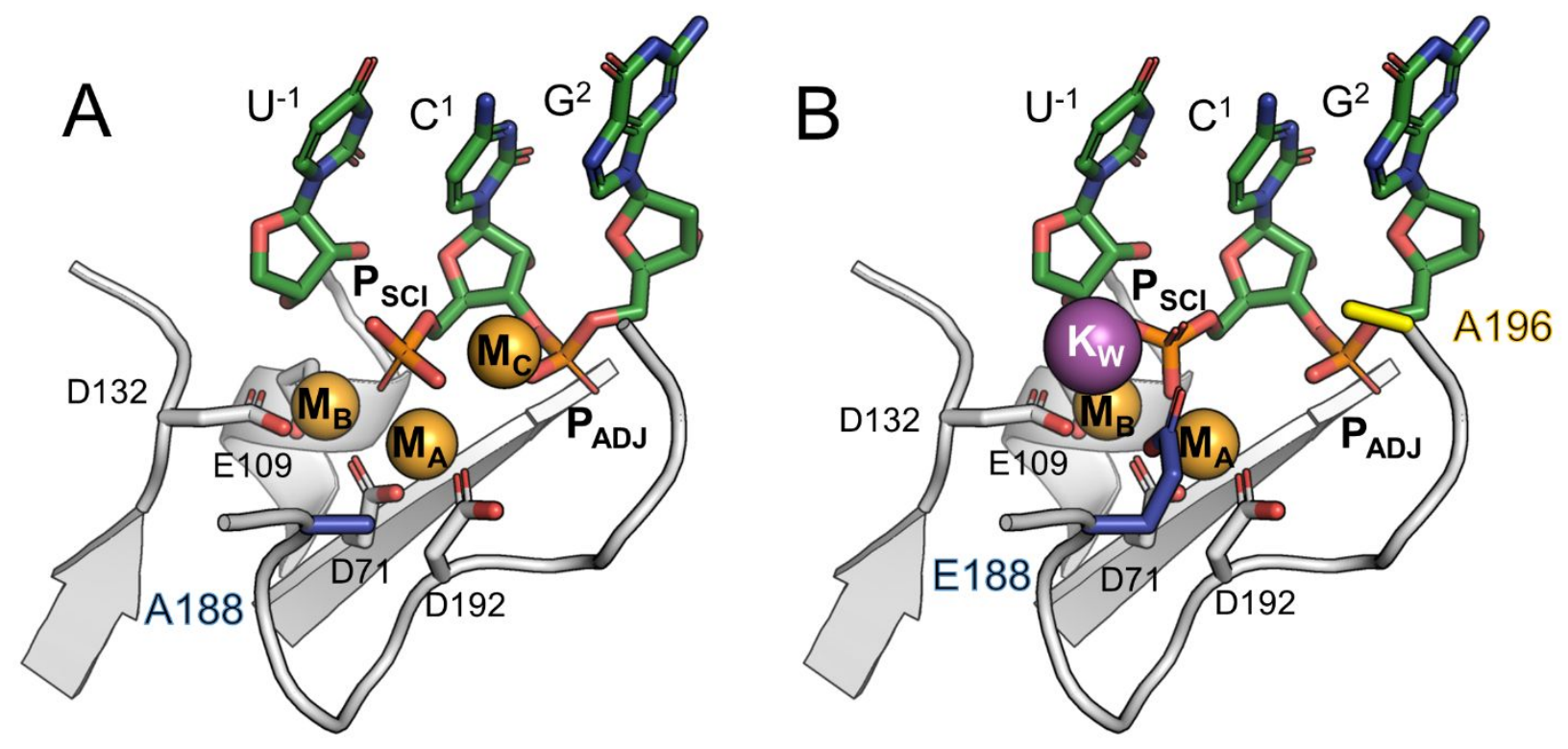

Figure S2. Reaction intermediates of RNase H1 mutants as captured by X-ray crystallography. (A)

The mutant E188A in the post-reactive state (PDBid: 6DPO), as obtained upon alanine mutation of the second-shell residue E188. The catalytic residues forming the DEDD motif (viz. D71, E109, D132, and D192; white) and the residue A188 (blue) are represented as sticks. The RNA nucleotides (green) including the scissile phosphate $\left(\mathrm{P}_{\mathrm{SCI}}\right)$ and its adjacent phosphate $\left(\mathrm{P}_{\mathrm{ADJ}}\right)$ are also shown as sticks. The two catalytic magnesium ions $\mathrm{M}_{\mathrm{A}}-\mathrm{M}_{\mathrm{B}}$ (orange) and the additional third $\mathrm{M}_{\mathrm{C}}$ ion (orange) are shown as spheres. Notably, in absence of the residue $\mathrm{E} 188, \mathrm{~K}_{\mathrm{W}}$ is not present in the vicinity of the active site, as opposite to what found in the wild type RNase H1 (B) The mutant K196A in the post-reactive state, as obtained upon alanine mutation of the second-shell residue K196 (PDBid: 6DPM). Here, the residues E188 (blue) and A196 (yellow) are represented as sticks, while the additional $\mathrm{K}_{\mathrm{W}}$ (purple) is shown as a sphere. Notably, in absence of K196, the configuration of the scissile phosphate is rotated and the additional metal ion $\mathrm{M}_{\mathrm{C}}$ does not locate at the active site. 
Reactant state

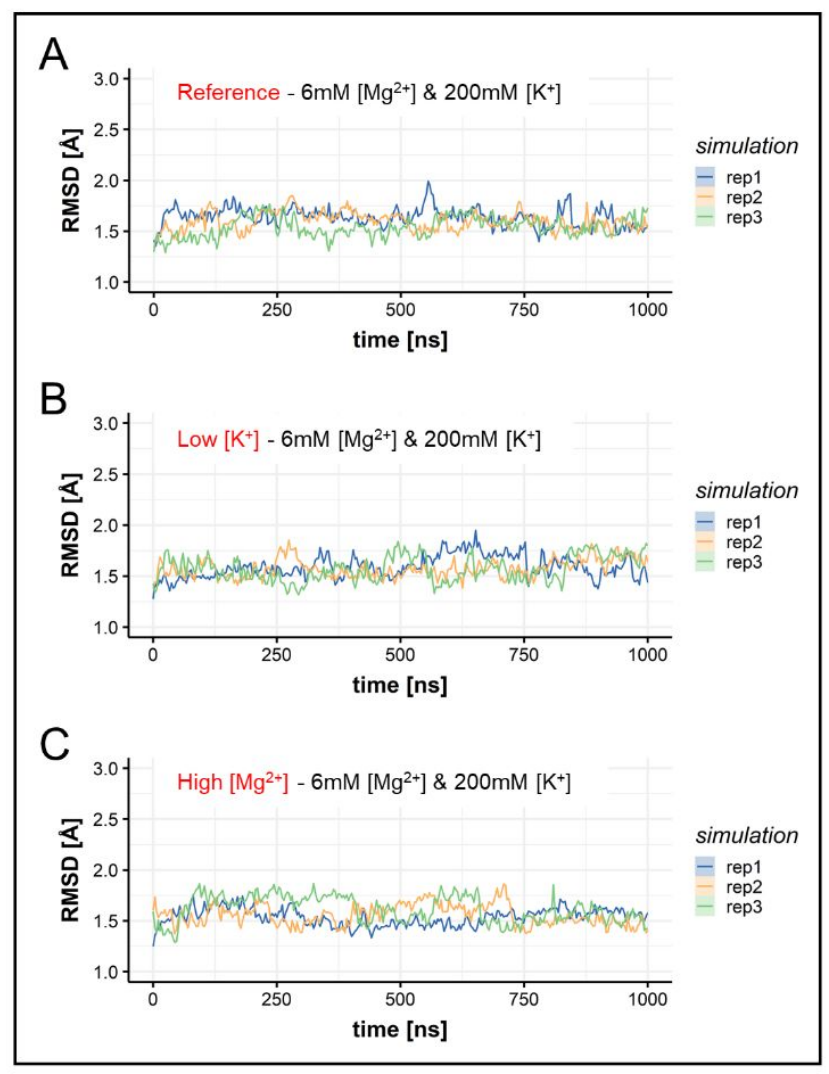

Product state

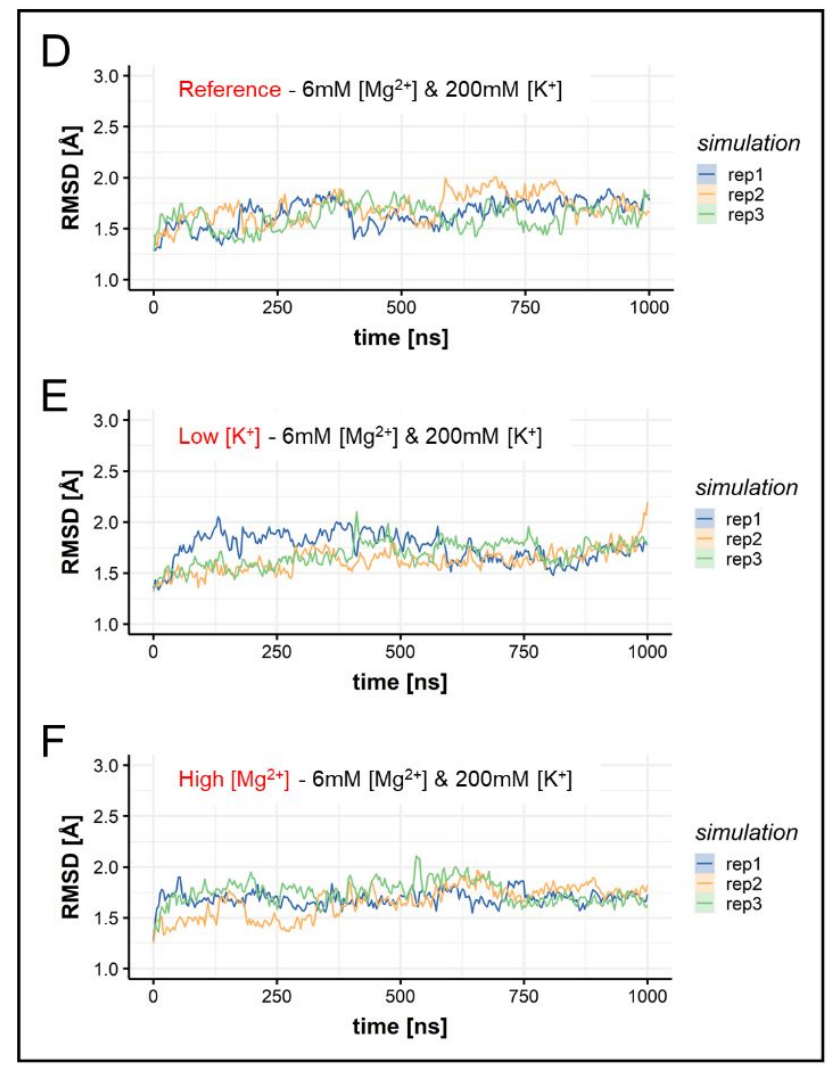

Figure S3. Root mean square deviation (RMSD) for the backbone atoms of RNase H1 during molecular dynamics (MD) simulations. On the right are shown the simulation replicas (blue, yellow, and green lines) of the RNase $\mathrm{H} 1$ in the reactant state at A) reference ionic strength; B) low $\mathrm{K}^{+}$ concentrations; C) high $\mathrm{Mg}^{2+}$ concentrations. On the left are reported the simulation replicas (blue, yellow, and green lines) of the RNase $\mathrm{H} 1$ in the product state at D) reference ionic strength; E) low $\mathrm{K}^{+}$ concentrations; F) high $\mathrm{Mg}^{2+}$ concentrations. Three simulation replicas were performed at each condition to verify the robustness of our observations. 

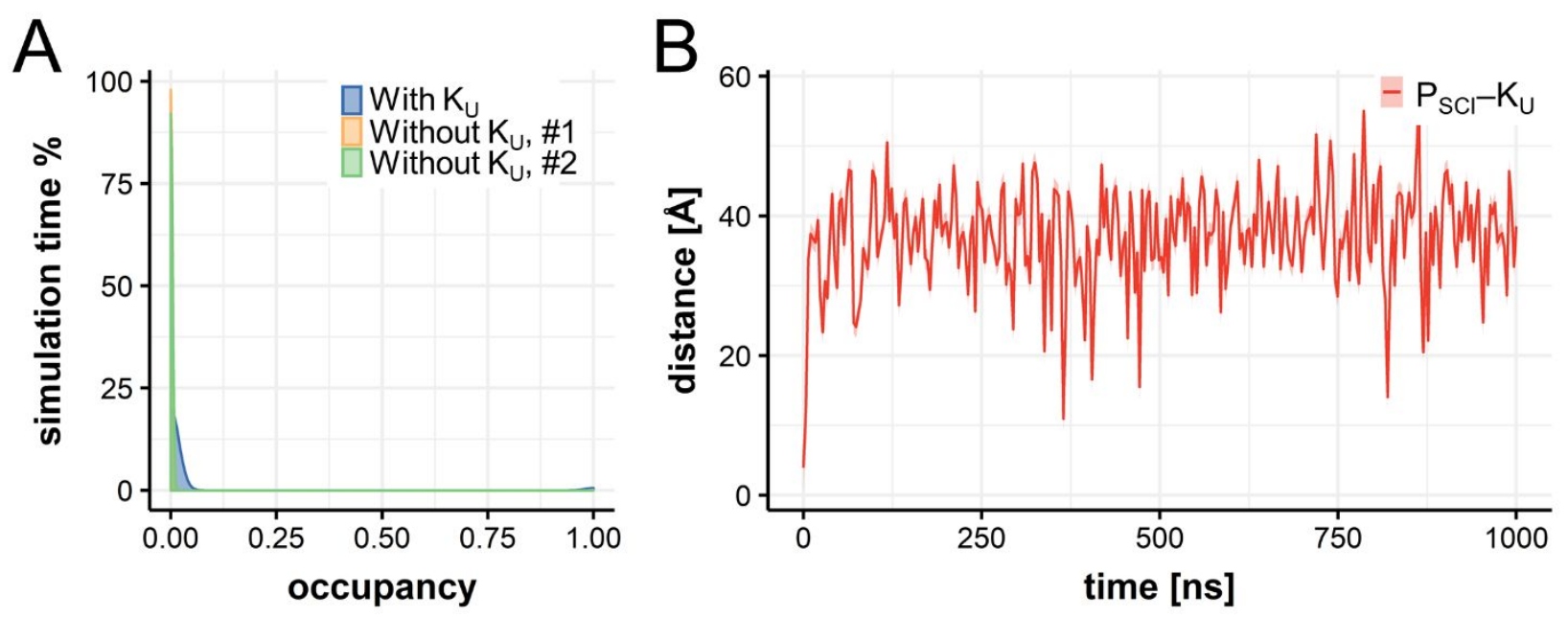

Figure S4. Mobility of $\mathbf{K}_{\mathbf{U}}$ in the reactant state. (A) Occupancy of the U-site averaged along three $\sim 1$ $\mu$ s-long MD simulations of RNase $\mathrm{H} 1$ in the reactant state (at optimal ionic strength, $6 \mathrm{mM}\left[\mathrm{Mg}^{2+}\right]$ and $200 \mathrm{mM}\left[\mathrm{K}^{+}\right]$) including $\mathrm{K}_{\mathrm{U}}$ (blue trace) and without $\mathrm{K}_{\mathrm{U}}$ (yellow and green traces). The almost null occupancy of $\mathrm{K}^{+}$ion at the U-site indicates that $\mathrm{K}_{\mathrm{U}}$ is not present during these simulations. (B) Distance between the scissile phosphate $\left(\mathrm{P}_{\mathrm{SCI}}\right)$ and $\mathrm{K}_{\mathrm{U}}\left(\mathrm{P}_{\mathrm{SCI}}-\mathrm{K}_{\mathrm{U}}\right)$ during $\sim 1 \mu \mathrm{s}$ MD simulations of RNase $\mathrm{H} 1$ in the reactant state. Here, $\mathrm{K}_{\mathrm{U}}$ was included in the starting conformation. However, the ion is immediately released into the bulk. 

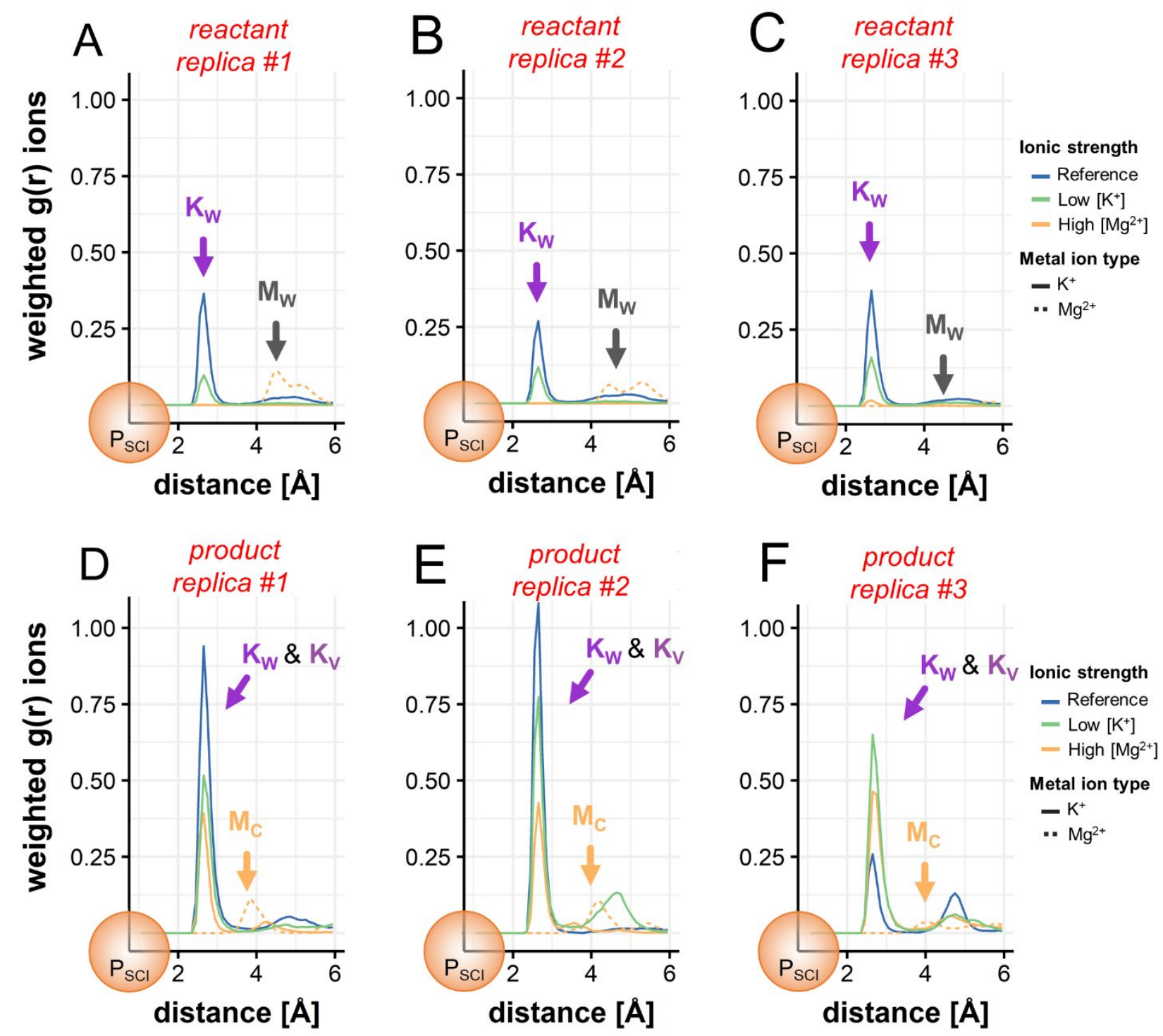

Figure S5. Distribution of the ions at the RNase $\mathrm{H} 1$ active site before and after RNA hydrolysis. (A-C) Weighted radius of gyration $\left(\mathrm{g}(\mathrm{r})\right.$ ) for $\mathrm{K}^{+}$(solid line) and $\mathrm{Mg}^{2+}$ (dashed line) ions around the scissile phosphate in the reactant state (viz. before hydrolysis), along three MD simulation runs of $\sim 1 \mu \mathrm{s}$ each, performed at optimal (blue trace, $6 \mathrm{mM}\left[\mathrm{Mg}^{2+}\right]$ and $200 \mathrm{mM}\left[\mathrm{K}^{+}\right]$), high $\mathrm{Mg}^{2+}$ (yellow trace, $85 \mathrm{mM}$ $\left[\mathrm{Mg}^{2+}\right]$ and $75 \mathrm{mM}\left[\mathrm{K}^{+}\right]$) and low $\mathrm{K}^{+}$(green trace, $6 \mathrm{mM}\left[\mathrm{Mg}^{2+}\right]$ and $25 \mathrm{mM}\left[\mathrm{K}^{+}\right]$) concentrations. Data are shown for three sets of simulation replicas. $\mathrm{K}_{\mathrm{W}}$ (purple arrow) is transiently captured at the active site at both high and low $\mathrm{K}^{+}$, but not at high $\mathrm{Mg}^{2+}$ concentrations, where an additional $\mathrm{M}_{\mathrm{W}}$ (grey arrow) binds with E188 (Figure S7D). Importantly, while panels (A-B) report data performed using the Aqvist model 
for $\mathrm{Mg}^{2+}$ ions, the Allnér force field has been employed to generate data reported in panel (C). The latter reveals a more flexible binding between $\mathrm{M}_{\mathrm{W}}$ and E188 (Figure S7C), resulting in a less pronounced $\mathrm{M}_{\mathrm{W}}$ weighted distribution peak. (D-F) The same descriptors as in panels (A-C) are reported for three sets of $\sim 1 \mu$ s-long simulation replicas of RNase $\mathrm{H} 1$ in the product state (viz. after hydrolysis). Here, regardless of the ionic strengths, $\mathrm{K}_{\mathrm{W}}$ (purple arrow) is stably captured at the active site, while transient binding of $\mathrm{K}_{\mathrm{V}}$ is also observed. At high $\mathrm{Mg}^{2+}$ concentration, the third $\mathrm{M}_{\mathrm{C}}$ is bound to the scissile phosphate. This binding event is mediated by first-shell coordination waters of $\mathrm{M}_{\mathrm{C}}$. Data reported in panel (F) have been collected employing the Allnér force field for $\mathrm{Mg}^{2+}$ ions, showing a weakened interaction between $\mathrm{M}_{\mathrm{C}}$ and the scissile phosphate, reducing the magnitude of $\mathrm{M}_{\mathrm{C}}$ peak. 

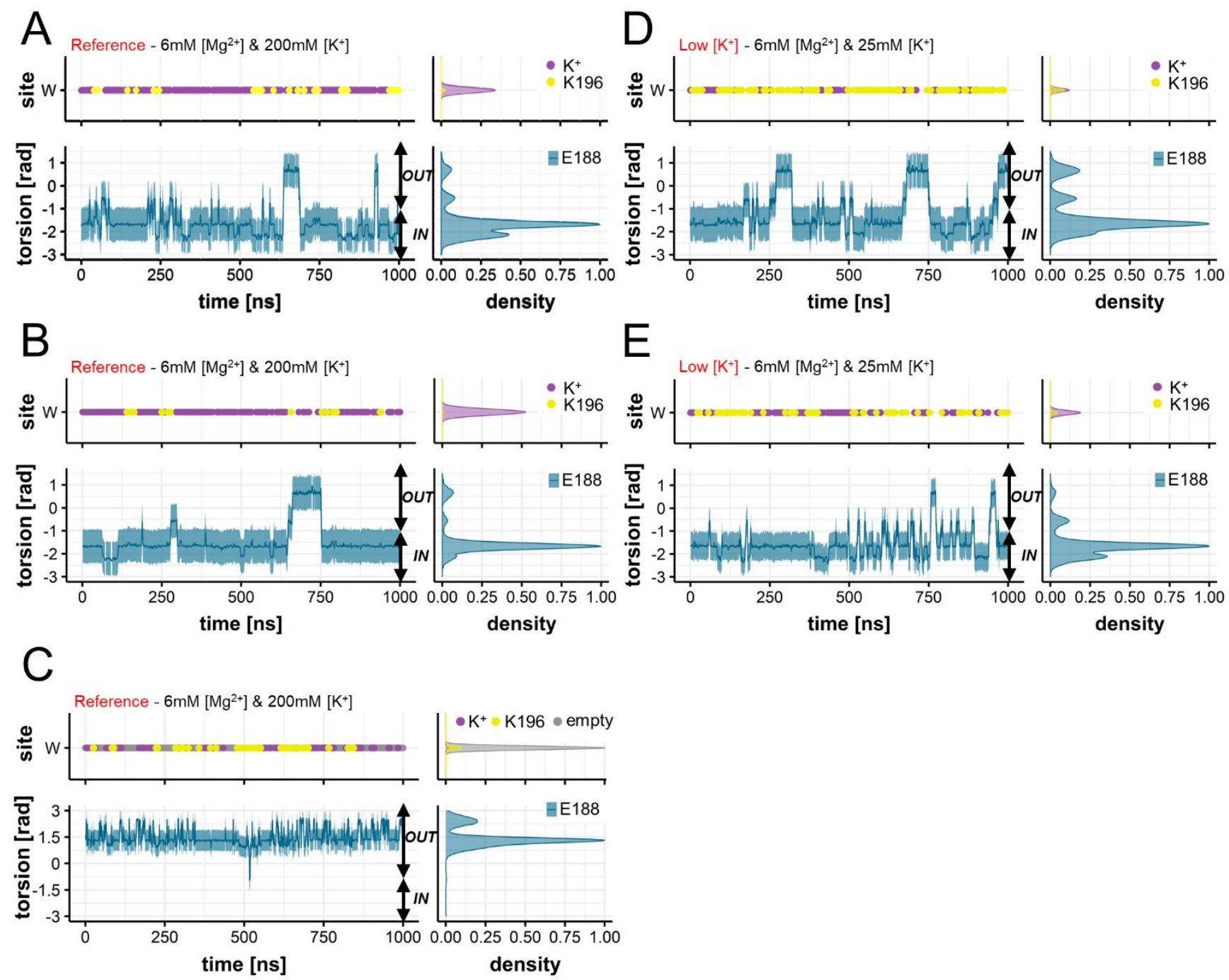

Figure S6. MD simulations replica of the RNase $\mathrm{H1}$ in the reactant state. (A-C) Occupancy of the W-site (upper panel) by $\mathrm{K}^{+}$ions (purple) and by the $\mathrm{K} 196$ residue (yellow); and variation of the torsional angle E188- $\theta$ (lower panel, computed between the $\mathrm{N}-\mathrm{C} \alpha-\mathrm{C} \beta-\mathrm{C} \delta$ atoms) along three additional MD replicas at optimal ionic strength $\left(6 \mathrm{mM}\left[\mathrm{Mg}^{2+}\right]\right.$ and $\left.200 \mathrm{mM}\left[\mathrm{K}^{+}\right]\right)$. Normalized densities are shown on the right. High concentrations of $\mathrm{K}^{+}$favor the binding of $\mathrm{K}_{\mathrm{W}}$ and the stabilization of $\mathrm{E} 188_{I N}$ conformation. An harmonic restraint has also been applied to E188 torsion $(\mathrm{N}-\mathrm{C} \alpha-\mathrm{C} \beta-\mathrm{C} \delta)$ during the replica reported in the panel (C). Here, as E188 cannot explore "in" conformations, the binding of $\mathrm{K}_{\mathrm{W}}$ is dramatically reduced. (D-E) The same descriptors reported as in panel (A), for two additional MD replicas at low $\mathrm{K}^{+}$ 
concentration. These MD replicas corroborate the synergistic interaction between $\mathrm{K}_{\mathrm{W}}$ and $\mathrm{E} 188$ for active site stabilization, as shown in Figure 2. 

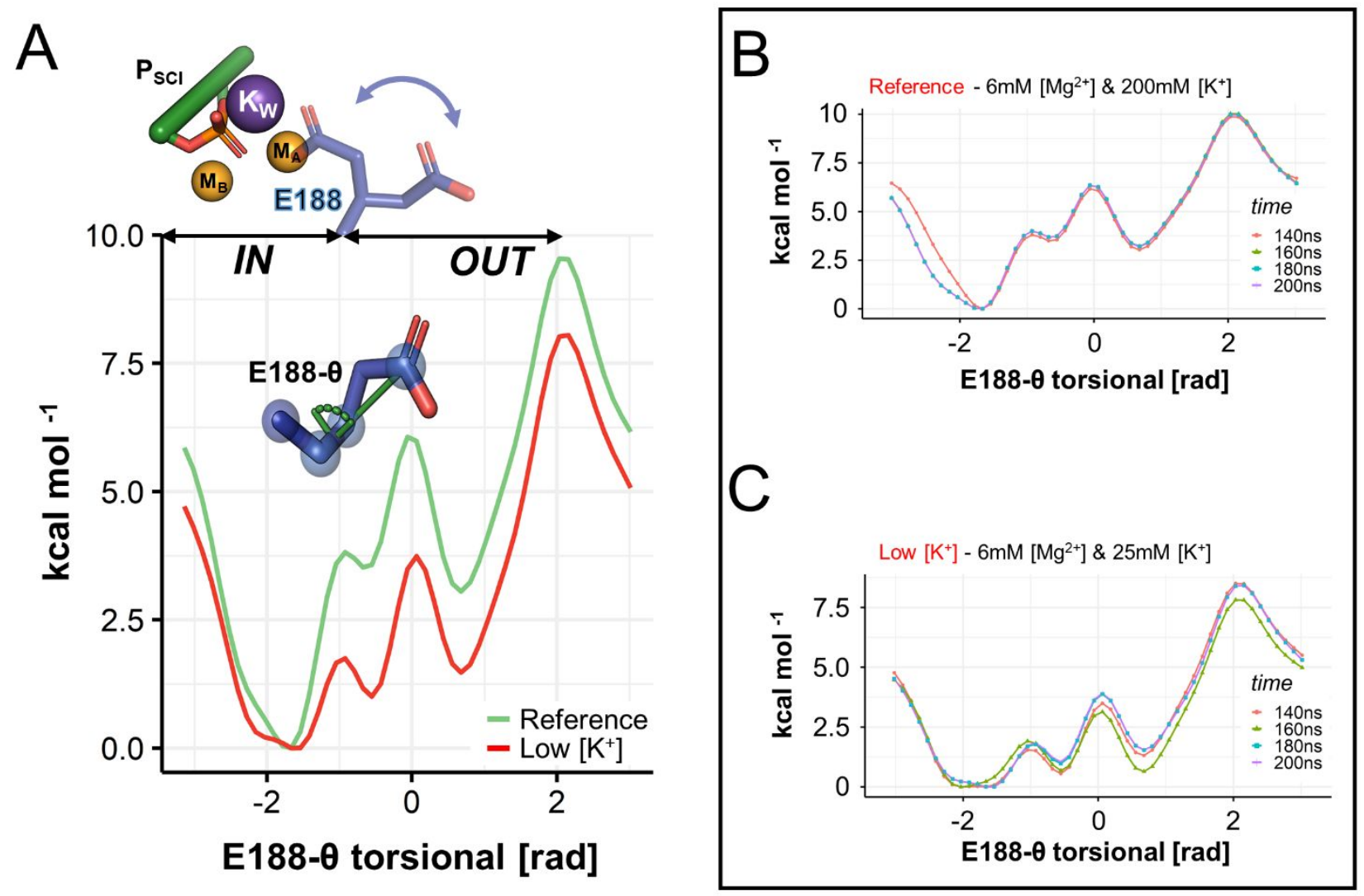

Figure S7. Metadynamics simulations for the E188 inner $\leftrightarrow$ outer conformational swing. (A) Top: the conformational change of E188 is shown (blue arrows); the residue E188 (blue) and the scissile phosphate $\left(\mathrm{P}_{\mathrm{SCl}}\right.$, green) are shown as sticks, while the ions $\mathrm{K}_{\mathrm{W}}$ (purple), $\mathrm{M}_{\mathrm{A}}-\mathrm{M}_{\mathrm{B}}$ (orange) are shown as spheres. Bottom: Free-energy profiles computed along the E188- $\theta$ torsional angle, using well-tempered metadynamics simulations. The inner $\leftrightarrow$ outer conformational swing of E188 is $\sim 2.3 \mathrm{kcal} \mathrm{mol}^{-1}$ less favored at reference (green) than at low (red) $\mathrm{K}^{+}$concentration. (B) The free energy for the inner $\leftrightarrow$ outer conformational of E188 is estimated as a function of time over non-overlapping windows of $\sim 20 \mathrm{~ns}$ during the last $\sim 60 \mathrm{~ns}$ of metadynamics (viz. from $\sim 140$ to $\sim 200 \mathrm{~ns}$ ) performed at optimal ionic strength $\left(6 \mathrm{mM}\left[\mathrm{Mg}^{2+}\right]\right.$ and $\left.200 \mathrm{mM}\left[\mathrm{K}^{+}\right]\right)$. (C) The free energy is estimated as in panel (A) along metadynamics simulations at low $\mathrm{K}^{+}$concentrations $\left(6 \mathrm{mM}\left[\mathrm{Mg}^{2+}\right]\right.$ and $\left.25 \mathrm{mM}\left[\mathrm{K}^{+}\right]\right)$. In both cases, after $\sim 160 \mathrm{~ns}$ no 
significant changes in the free energy profiles are detected, suggesting that both the metadynamics simulations are converged. 

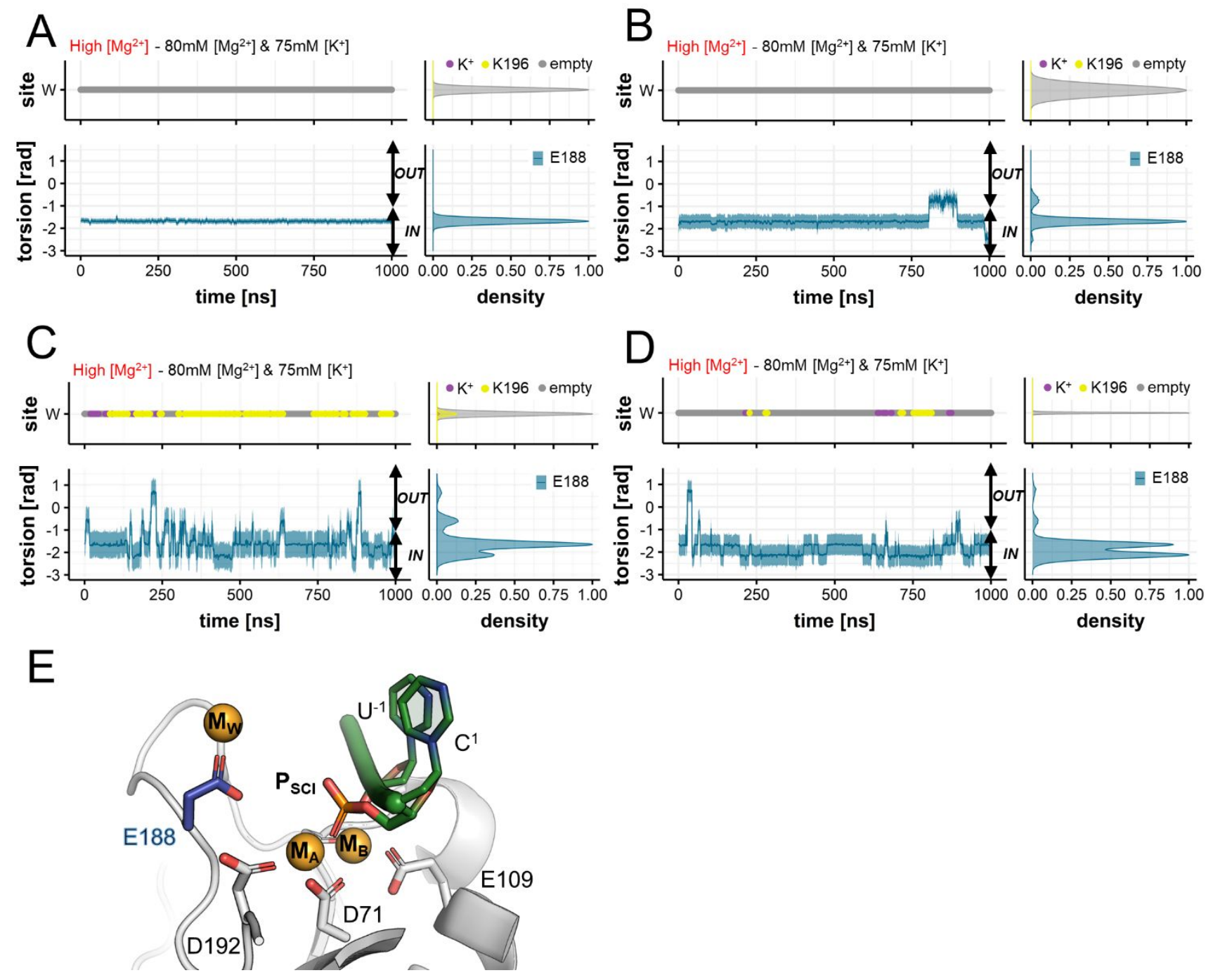

Figure S8. MD simulations of RNase $\mathrm{H1}$ in the reactant state at high $\mathrm{Mg}^{2+}$ concentrations. (A-D)

The occupancy of the $\mathrm{W}$-site by $\mathrm{K}^{+}$ions and by the K196 residue together with the variation of the torsional angle E188- $\theta$ (computed between the $\mathrm{N}-\mathrm{C} \alpha-\mathrm{C} \beta-\mathrm{C} \delta$ atoms) are reported for three MD replicas at high $\mathrm{Mg}^{2+}$ concentration $\left(80 \mathrm{mM}\left[\mathrm{Mg}^{2+}\right]\right.$ and $\left.75 \mathrm{mM}\left[\mathrm{K}^{+}\right]\right)$, following the same scheme as in Figure S5. Despite $\mathrm{E} 188_{I N}$ conformation is stabilized, no $\mathrm{K}^{+}$ions are captured at $\mathrm{W}$-site because an additional $\mathrm{Mg}_{2+}$ metal $\left(v i z . \mathrm{M}_{\mathrm{W}}\right.$ ) binds with E188 closing the accessibility of the $\mathrm{W}$-site to $\mathrm{K}^{+}$ions. Importantly, panels (A-C) report data performed using 12-6 model for $\mathrm{Mg}^{2+}$ ions (A-B, Aqvist; C, Allnér), while in panel (D) the $\mathrm{Mg}^{2+}$ ions were modeled according to $12-6-4$ model from Panteva. Both the simulations performed with Allnér and Panteva force field parameters showed a weakened interaction between $\mathrm{M}_{\mathrm{W}}$ 
and the E188. However, the interaction between $\mathrm{M}_{\mathrm{W}}$ and E188 still occurs, preventing the binding of $\mathrm{K}^{+}$ at the W-site, which is only transiently occupied by K196. (E) Structural representation of $\mathrm{M}_{\mathrm{W}}$ binding preventing the E188-mediated recruitment of $\mathrm{K}_{\mathrm{W}}$ at W-site. The active site of RNase $\mathrm{H} 1$ is represented according to Figure S1. Together, these MD simulations corroborate the fundamental role of E188 in the recruitment of $\mathrm{K}_{\mathrm{W}}$ - as shown in Figure 2 - and provide a rationale for the attenuation of RNase H1 catalysis at high $\mathrm{Mg}^{2+}$ concentrations. 

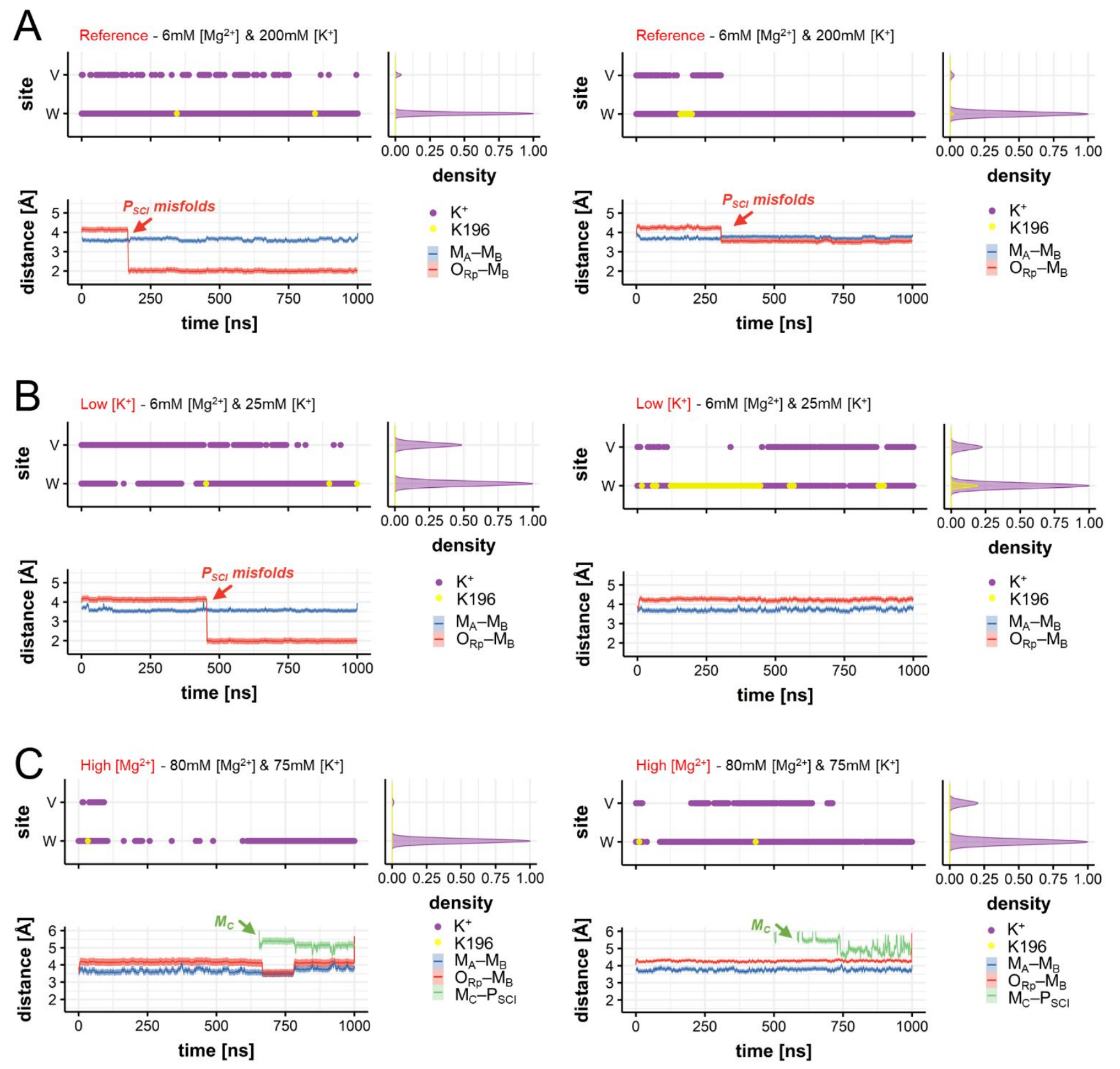

- $\mathrm{K}^{+}$
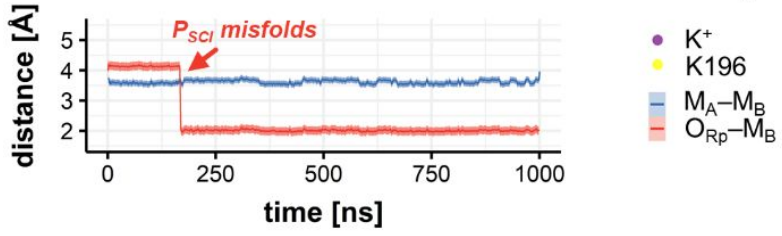

$\mathrm{O}_{\mathrm{Rp}}-\mathrm{M}_{\mathrm{B}}$ 
Figure S9. MD simulations of RNase $\mathrm{H1}$ in the product state. (A) Occupancy of the W- and the Vsite (upper panel) by $\mathrm{K}^{+}$ions (purple) and K196 side chain (yellow); and the distances (lower panel) between the catalytic ions $\mathrm{M}_{\mathrm{A}}-\mathrm{M}_{\mathrm{B}}\left(\mathrm{M}_{\mathrm{A}}-\mathrm{M}_{\mathrm{B}}\right.$, blue trace) and between the pro- $\mathrm{R}$ oxygen $\left(\mathrm{O}_{\mathrm{Rp}}\right)$ of the scissile phosphate and the metal $\mathrm{M}_{\mathrm{B}}\left(\mathrm{O}_{\mathrm{Rp}}-\mathrm{M}_{\mathrm{B}}\right.$, red trace) during two MD replicas at optimal ionic strength (right and left panels). Normalized densities are shown on the right of each panel. After the RNA hydrolysis both $\mathrm{K}_{\mathrm{W}}, \mathrm{K}_{\mathrm{V}}$ and $\mathrm{K} 196$ concurrently interact with the products as a consequence of their binding at the $\mathrm{W}$ - or the $\mathrm{V}$-site. Despite the scissile phosphate $\left(\mathrm{P}_{\mathrm{SCI}}\right)$ get misfolded when only $\mathrm{K}_{\mathrm{W}}$ locates at the active site, this event does not favor the release of the products as the two catalytic ions $M_{A}-M_{B}$ are stabilized at their position. (B) The same descriptors as in panel (A) are shown for two MD replicas at low $\mathrm{K}^{+}$concentrations. At this ionic strength, the binding of $\mathrm{K}^{+}$ions at the $\mathrm{W}$ - or $\mathrm{V}$ - site is less recurrent, and thus these ion exchange more frequently its position with the residue K196. This seems to favor the product stabilization. (C) The same descriptors as in panel (A) are shown for two MD replicas at high $\mathrm{Mg}^{2+}$ concentrations. Additional distance between $\mathrm{M}_{\mathrm{C}}$ and scissile phosphate is reported as green trace $\left(\mathrm{M}_{\mathrm{C}}-\mathrm{SP}\right)$. Despite two different $\mathrm{Mg}^{2+}$ models have been used in the two MD simulations, Aqvist (left) and Allnér (right), the additional $\mathrm{M}_{\mathrm{C}}$ gets recruited at the active site to coordinate the scissile phosphate in both the simulations. As a consequence of this binding event the distance $\mathrm{M}_{\mathrm{A}}-\mathrm{M}_{\mathrm{B}}$ is increased, suggesting that the active site is now prone to release the reaction products. (D) The same descriptors as in panel (A) are shown for two MD replicas at high $\mathrm{Mg}^{2+}$ concentrations, performed using the Panteva 12-6-4 model for $\mathrm{Mg}^{2+}$ ions. These simulations are in good agreement with those reported in panel (C). Together, these MD replicas sustain the role of $\mathrm{K} 196, \mathrm{~K}_{\mathrm{W}}$, and $\mathrm{K}_{\mathrm{V}}$ in the stabilization of the scissile phosphate for the recruitment of $\mathrm{M}_{\mathrm{C}}$ and product release, in agreement with the findings showed in Figure 3. 


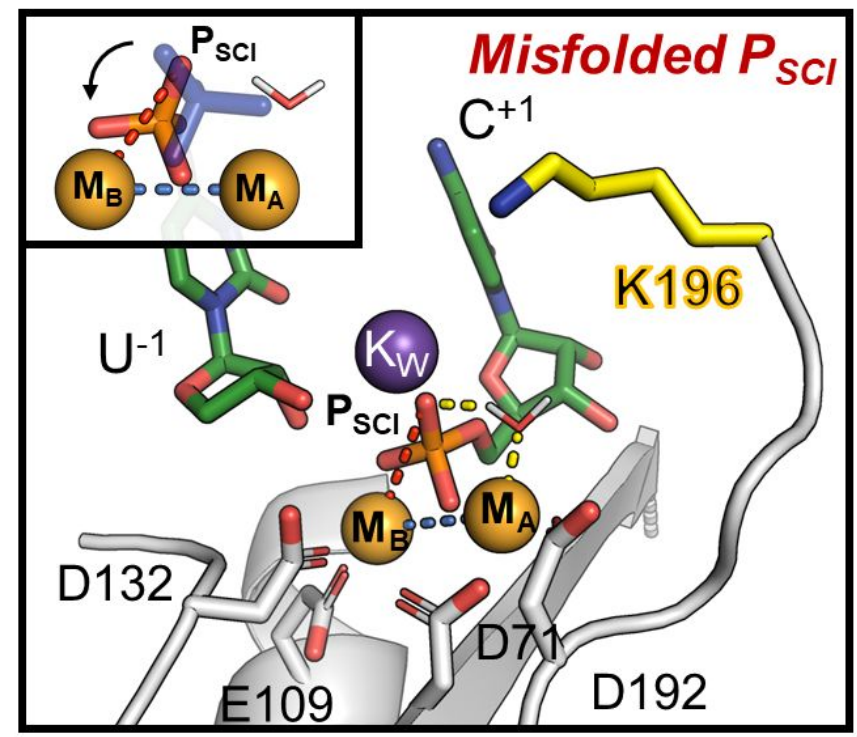

Figure S10. Structural representation of the scissile phosphate misfolding. MD simulations of the RNase $\mathrm{H} 1$ in the product state shown that the scissile phosphate $\left(\mathrm{P}_{\mathrm{SCI}}\right)$ can, at times, rotate around the phosphodiester bond. Upon rotation, one bulky water molecule replaces the phosphate oxygen to coordinate the catalytic $\mathrm{M}_{\mathrm{A}}$. This event occurs when only $\mathrm{K}_{\mathrm{W}}$ is bound at the active site, while $\mathrm{K}_{\mathrm{V}}$ and K196 are unbound (main panel). Notably, the misfolded conformation observed in our MD simulations perfectly matches that captured in the K196 mutant by X-ray crystallography (top corner, orange sticks; PDBid: 6DPM). The conformation of the scissile phosphate as crystallized in the wild type RNase H1 is shown in the top corner (blue semi-transparent sticks, PDBid: 6DOG). All the representations are colorcoded as in Figure 1. 


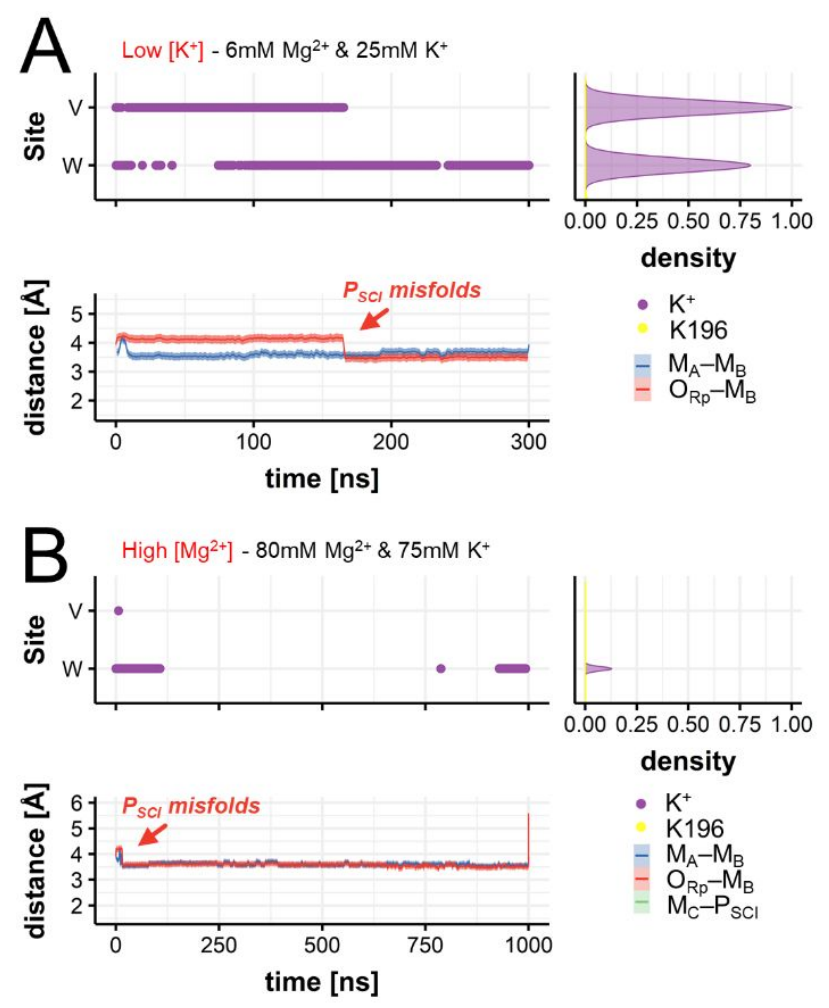

Figure S11. MD simulations of RNase H1 mutant K196A in the product state. (A) Occupancy of the W- and the V-site (upper panel) by $\mathrm{K}^{+}$ions (purple) and for the K196 (yellow); and the distances (lower panel) between the catalytic ions $M_{A}-M_{B}\left(M_{A}-M_{B}\right.$, blue trace) and between the pro- $R$ oxygen $\left(O_{R p}\right)$ of the scissile phosphate and the $\mathrm{M}_{\mathrm{B}}$ ion $\left(\mathrm{O}_{\mathrm{Rp}}-\mathrm{M}_{\mathrm{B}}\right.$, red trace) during two $\mathrm{MD}$ replicas at low $\mathrm{K}^{+}$ concentration. Normalized densities are shown on the right. The absence of K196 induces the fast misfolding of the scissile phosphate $\left(\mathrm{P}_{\mathrm{SCI}}\right)$. (B) The same descriptors as in panel (A) are reported for MD simulations at high $\mathrm{Mg}^{2+}$ concentration. Here, the scissile phosphate is rotated and $\mathrm{M}_{\mathrm{C}}$ is not recruited at the active site, as opposite to what observed for the wild type RNase H1 MD simulations performed at the same high $\mathrm{Mg}^{2+}$ concentration (Figure 3C and $\mathbf{S 8 C}$ ). 


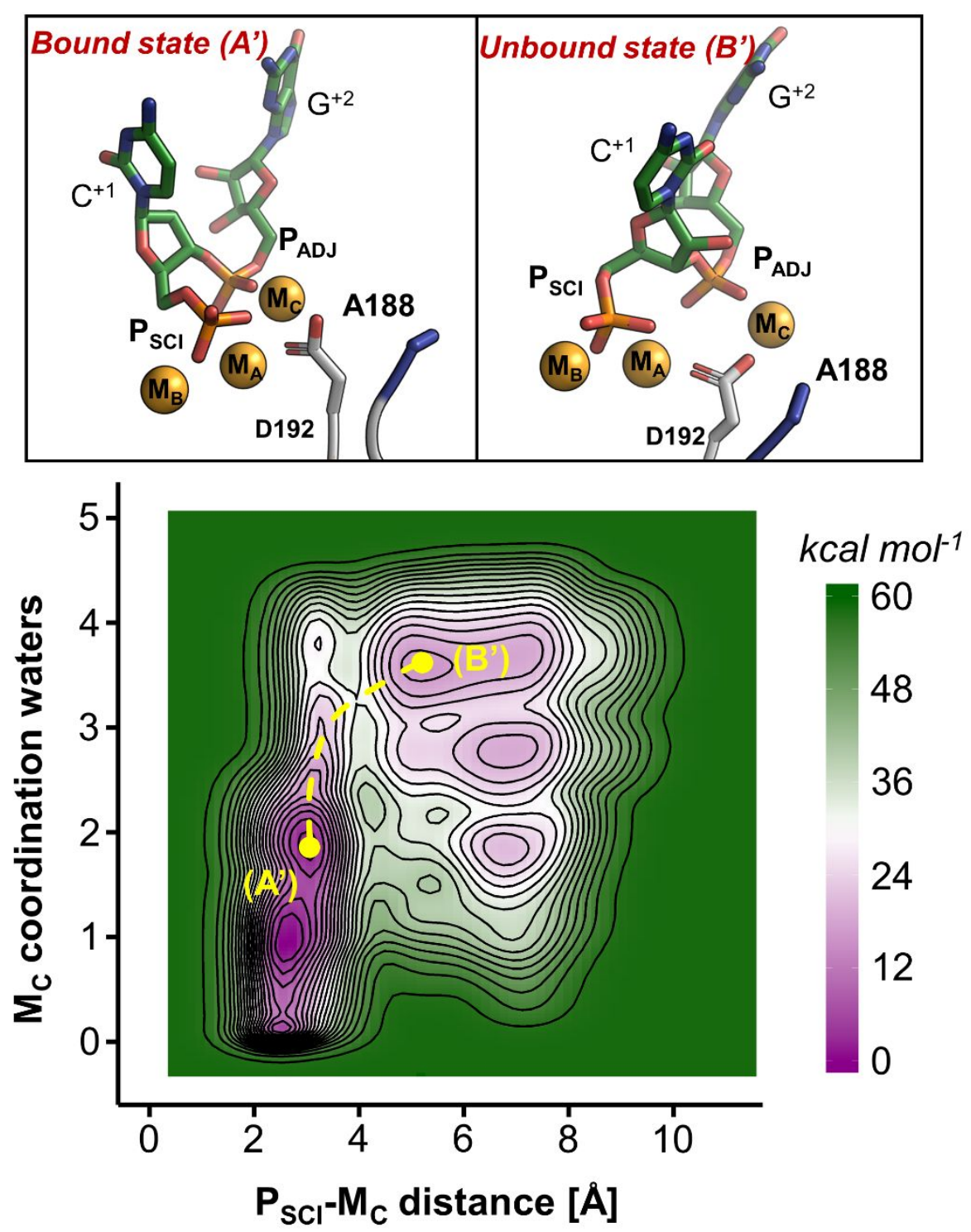

Figure S12. Metadynamics simulation of the RNase H1 mutant E188A in the product state. Structural representation of the metastable state A' and B' (upper panel) corresponding to the two main minima highlighted on the free energy surface (bottom panel). The energy scale is indicated in $\mathrm{kcal} \mathrm{mol}^{-1}$, while contour traces are reported every $3 \mathrm{kcal} \mathrm{mol}^{-1}$. In absence of the residue E188, the release of the third $\mathrm{M}_{\mathrm{C}}$ is guided by D192, which is not as efficient as E188 in shuttling the $\mathrm{M}_{\mathrm{C}}$ out of the active site together with the products. The free energy barrier associated with the $A^{\prime} \rightarrow B^{\prime}$ transition (bound $\rightarrow$ unbound state) is estimated at $\sim 35 \mathrm{kcal} \mathrm{mol}^{-1}$, while the state $\mathrm{A}^{\prime}$ is $\sim 18 \mathrm{kcal} \mathrm{mol}^{-1}$ more stable than the state B'. 

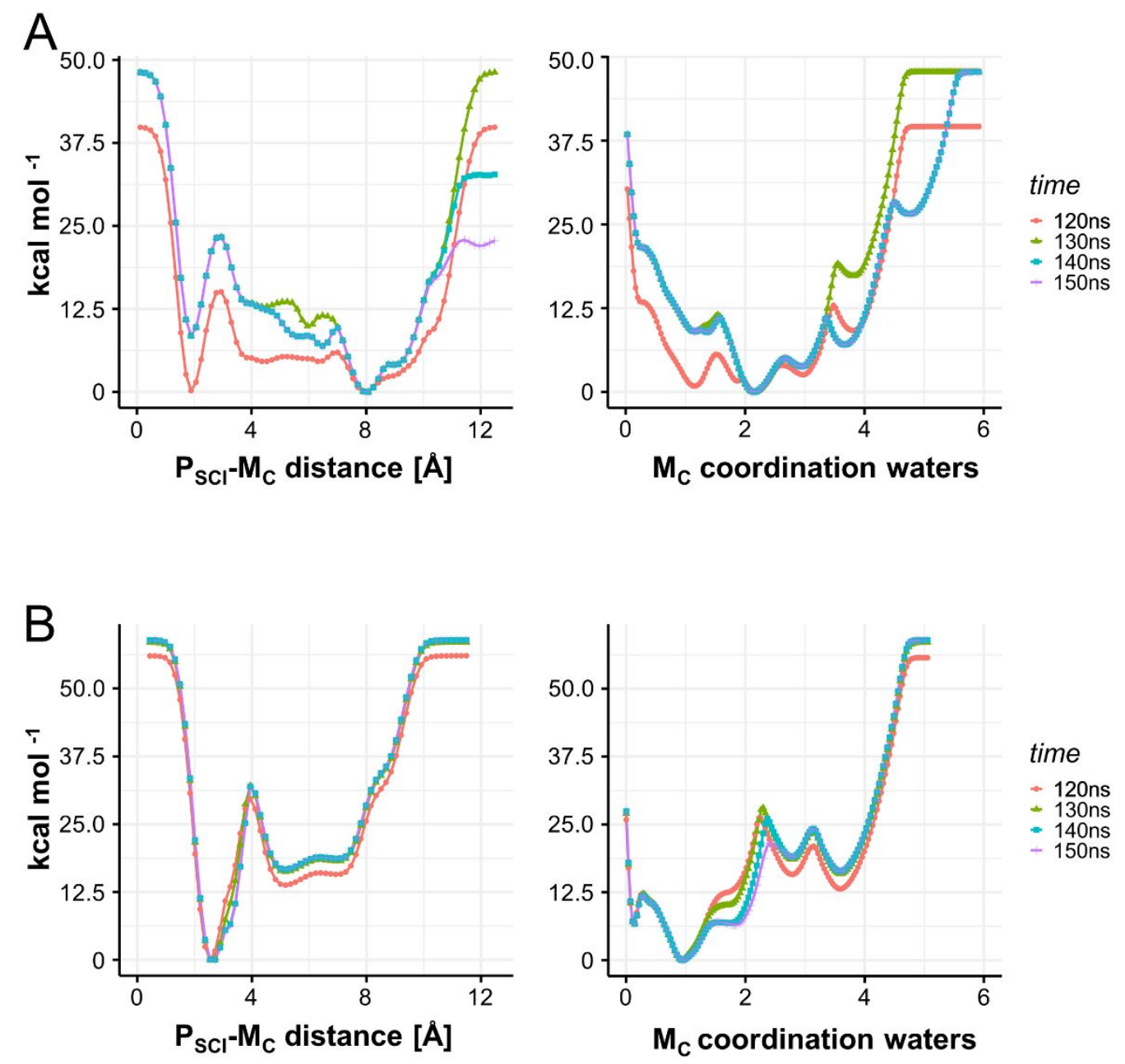

Figure S13. The convergence of the free energy profiles for the unbinding of $\mathbf{M}_{C}$ metal. (A) Free energy profiles projected on the distance between the scissile phosphate $\left(\mathrm{P}_{\mathrm{SCI}}\right)$ and the third $\mathrm{M}_{\mathrm{C}}$ ion $\left(\mathrm{P}_{\mathrm{SCI}}-\right.$ $\mathrm{M}_{\mathrm{C}}$ distance, left panel) and on the number of $\mathrm{M}_{\mathrm{C}}$ coordination water $\left(\mathrm{M}_{\mathrm{C}}\right.$ coordination waters, right panel) as obtained from metadynamics simulations in the wild type RNase H1. The free energy profiles are computed over non-overlapping windows of $\sim 10 \mathrm{~ns}$, considering the last $\sim 30 \mathrm{~ns}$ of simulations (viz. from $\sim 120$ to $150 \mathrm{~ns}$ ). (B) The free energy profiles are estimated as in panel (A) for the metadynamics simulations of the E188A mutant. In both the simulations, after $\sim 120$ ns no significant changes in the free energy profiles are detected, suggesting that both the metadynamics calculations are converged. 


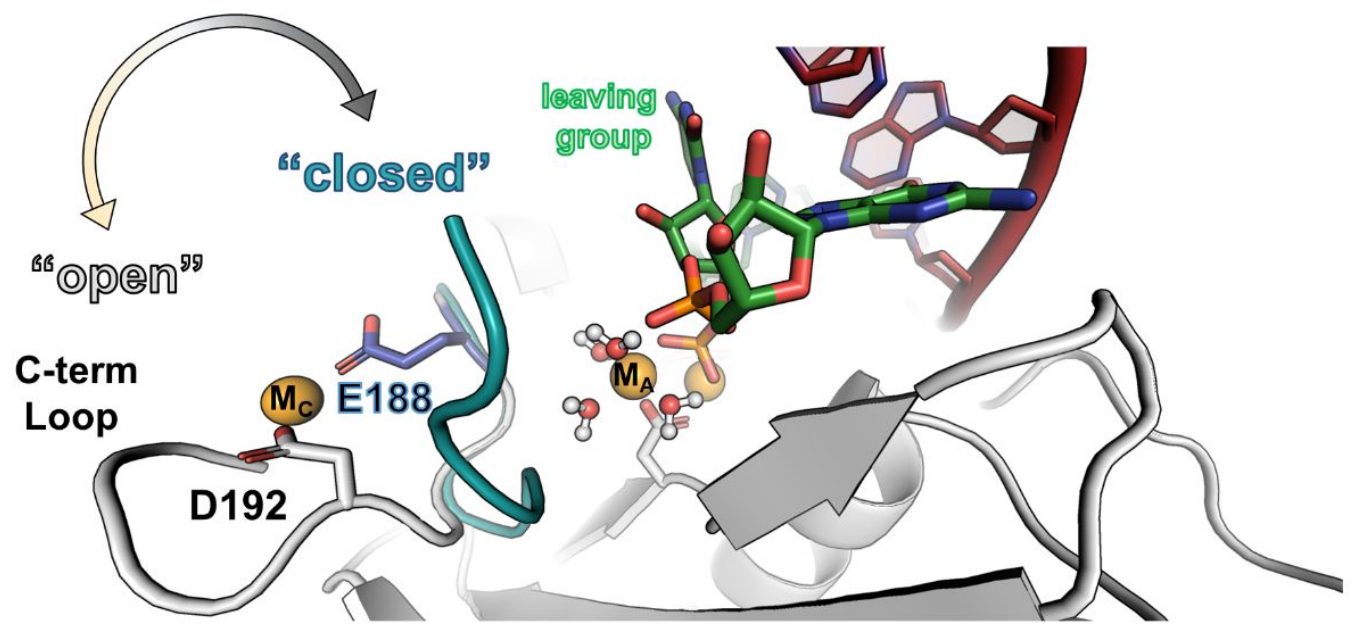

Figure S14. Release of $M_{C}$ and hydration of the active site for products' release. RNase H1 (white) and DNA (red) are shown as cartoons, while RNA leaving group (green), the second-shell residue E188 (blue), and the catalytic residue D192 (white) are represented as sticks. The catalytic $\mathrm{M}_{\mathrm{A}}-\mathrm{M}_{\mathrm{B}}$ ions and the third $\mathrm{M}_{\mathrm{C}}$ metals are shown as orange spheres. As observed in the metadynamics simulations of wild type RNase $\mathrm{H} 1, \mathrm{M}_{\mathrm{C}}$ gets coordinated by both the second-shell residue E188 and the catalytic D192. Here, the mobile C-terminal loop is in the "closed" state (blue cartoon). Upon the rotation of E188, both $\mathrm{M}_{\mathrm{C}}$ and the adjacent phosphate are shuttled out of the active site, while D192 loses the coordination with $\mathrm{M}_{\mathrm{A}}$. As a result of this conformational change, the C-terminal loop rearranges in the "open" state (white cartoon), favoring the hydration of the catalytic $\mathrm{M}_{\mathrm{A}}$ and, eventually, the release of the reaction products. 


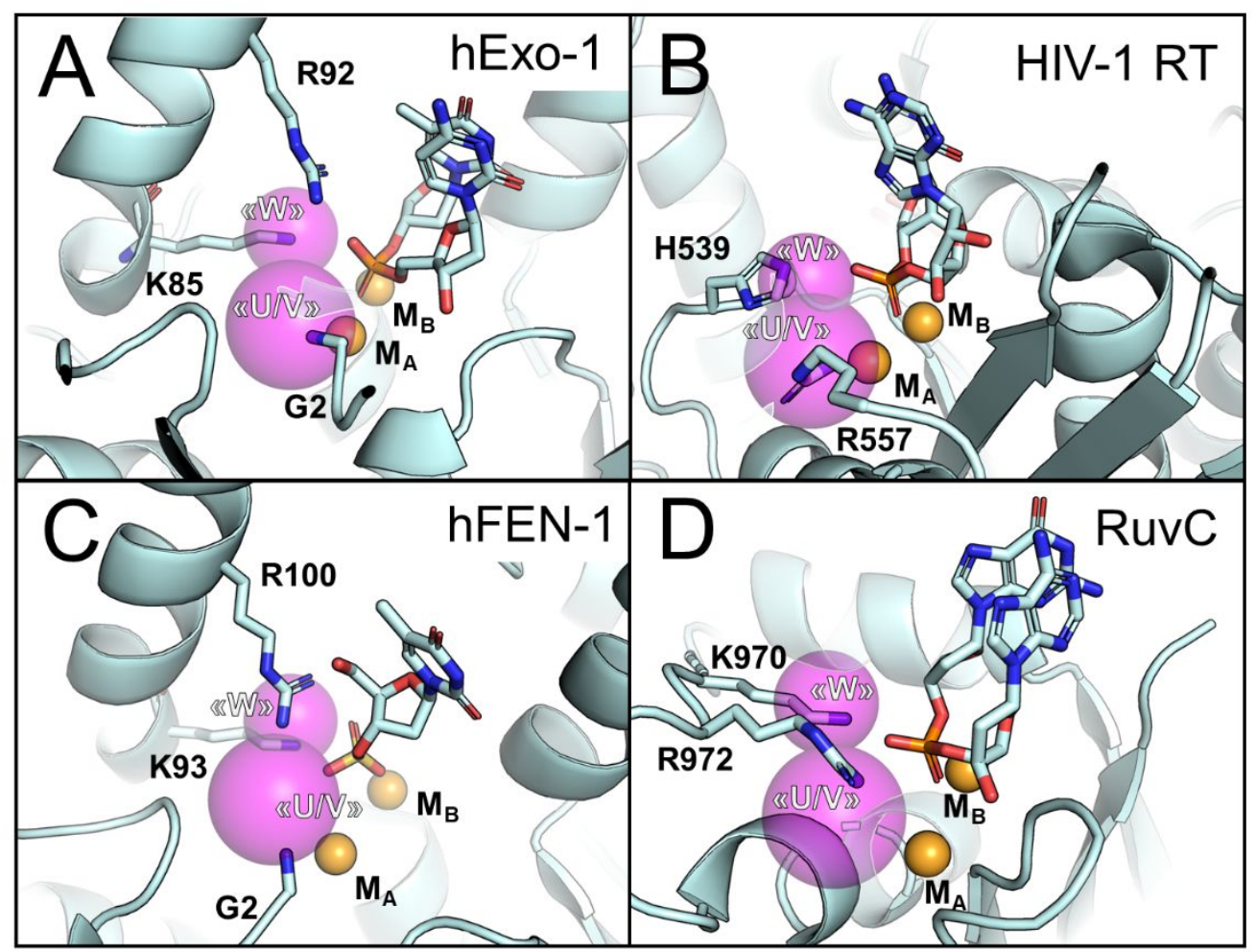

Figure S15. Structural overlap of positive charges at the active site of RNase H1, hExo-1, HIV-1 RT, and hFEN-1. The binding site "W", "U", and "V" (purple semi-transparent spheres) at the active site of RNase $\mathrm{H} 1$ are superimposed on the reaction center of $\mathbf{A}$ ) of hExo-1, B) HIV-1 reverse transcriptase (RT), C) hFEN-1, and D) RuvC catalytic domain of CRISPR-Cas9 system (cyan cartoon). The catalytic ions $\mathrm{M}_{\mathrm{A}}-\mathrm{M}_{\mathrm{B}}$ (orange) are shown as spheres, while the substrate/product (cyan) is represented as sticks. Remarkably, the position of structured residues (cyan sticks) located at the core of either hExo-1 (G2, K85, R95), or HIV-1 RT (R539, R557), or hFEN-1 (G2, K93, R100), or RuvC (K970, R972) well superimpose with the additional metals' binding sites "W", "U", and "V" at the active site of RNase H1. 


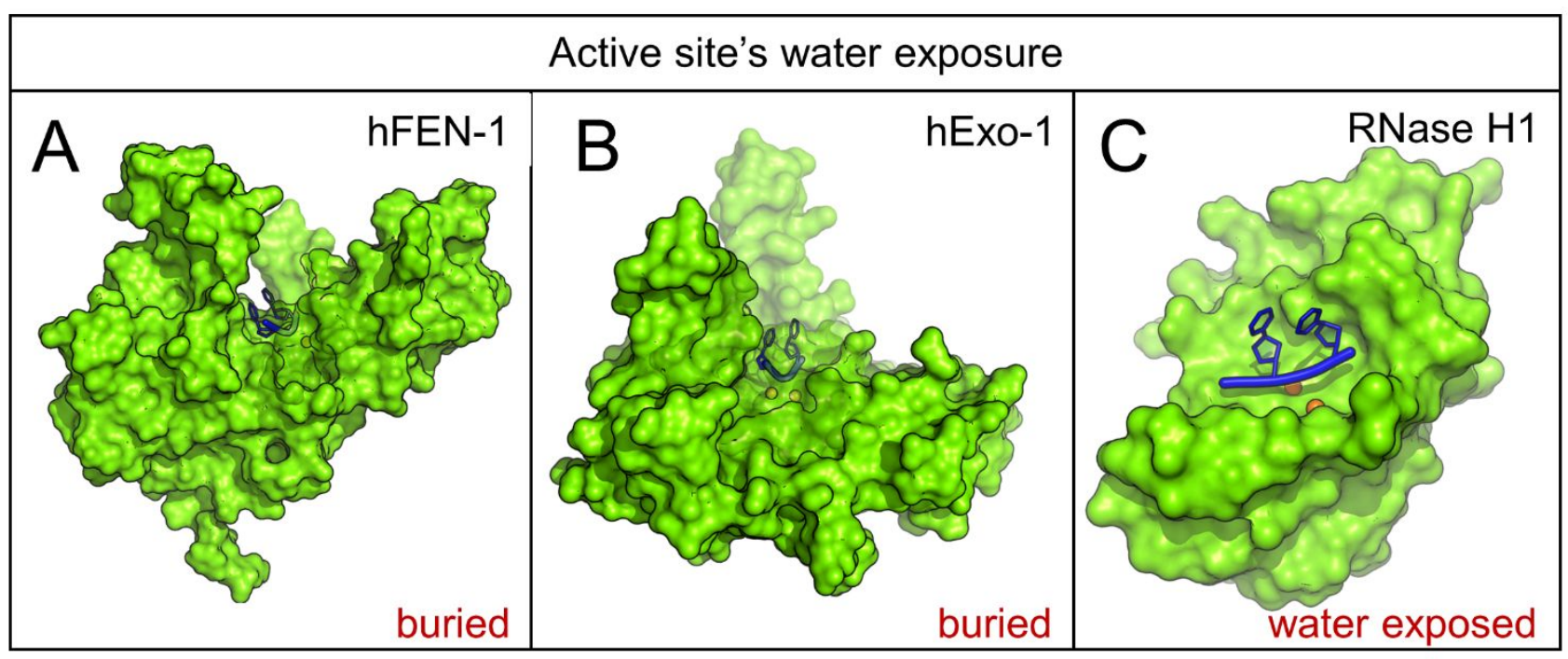

Figure S16. The active site of RNase $\mathrm{H1}$ is highly hydrated as compared to other nucleases. The surface (green), the catalytic metals (orange spheres), and the reaction substrate (blue cartoon) at the catalytic center are shown for (A) hExo-1, (B) hFEN-1, and (C) for RNase H1. In the first two nucleases, the active site is buried inside the protein (transparent green surface), while in RNase H1 the active site is completely exposed to the bulk solvent and ions. 